\title{
MORPHOMETRIC VARIATION OF HYBRIDIZING SPECIES AND GYNOGENETIC BIOTYPES OF SPINED LOACHES (COBITIDAE, COBITIS) IN RIVER SYSTEMS OF UKRAINE
}

\author{
Schmalhausen Institute of Zoology of NAS of Ukraine, \\ vul. B. Khmelnytskogo, 15, Kyiv, 01030 Ukraine \\ E-mail:smezhzherin@gmail.com \\ ${ }^{*}$ Corresponding author \\ S. V. Mezhzherin (http://orcid.org/0000-0003-2905-5235) \\ L. I. Pavlenko (http://orcid.org/0000-0002-5295-4258) \\ A. O. Tsyba (https://orcid.org/0000-0001-5838-0948) \\ T. V. Saliy (https://orcid.org/0000-0003-2961-1326) \\ M. A. Ghazali (http://orcid.org/0000-0001-9195-0914)
}

S. V. Mezhzherin^, L. I. Pavlenko, A. O. Tsyba, T. V. Saliy, M. A. Ghazali

Morphometric Variation of Hybridizing Species and Gynogenetic Biotypes of Spined Loaches (Cobitidae, Cobitis) in River Systems of Ukraine. Mezhzherin, S. V., Pavlenko, L. I., Tsyba, A. O., Saliy, T. V., Ghazali, M. A. - To test the possibility of identifying the species and biotypes of spined loaches of the complex Cobitis elongatoides-taenia-tanaitica using body morphometric characteristics, we considered a pool of specimens from different river systems of Ukraine. The sample included three parental species and seven hybrid biotypes with various genome combinations, and the morphometry was based on 23 body parameters and 26 derivative indices. The variability was analyzed by standard and multivariate statistics. Neither any one measurement, nor their combination allowed identifying the specimens with $95-100 \%$ probability. Pooled, samples had no internal logic of morphological remoteness of hybrid biotypes and parental species in regards to their genetic similarity. Morphometry's low resolution in case of pooled samples is linked to the specifics of body shape and significant geographic variability which partially evens out the between-group differences, while within samples the resolution was higher without reaching even $95 \%$ diagnostical certainty. All in all, the resolutions obtained for morphometric parameters are within results obtained in similar studies for other hybrid fishes.

Key words: morphometry, diagnostics, diploid-polyploid complex, spined loaches, Cobitis. 
True spined loach of the genus Cobitis Linnaeus, 1758 have Trans-Palearctic range with Eastern Asian and Mediterranean-European centers of species diversity. They have for two decades now attracted much attention from scientists working on unsolved problems on the border of evolutional genetics and systematics (Rab et al., 2000; Mezhzherin, Chudakorova, 2002; Janko et al., 2003, 2005, 2007; Culing et al., 2006; Perdices et al., 2016). The special interest towards the group of small fishes is two-fold; firstly, they exhibit an extraordinary taxonomic diversity, often cryptic if only the outer appearance is taken into account. Therefore, when karyotype diversity (Vasil'ev, 1985; Vasil'ev, Vasil'eva, 1998; Rab et al., 2000; Boroń, 2003; Mezhzherin et al., 2014), allozymes (Ślechtova et al., 2000; Mezhzherin, Pavlenko, 2010) and primary DNA structure (Culing et al., 2006; Perdices et al., 2016) began to be analyzed, within the morphological continuum of the erstwhile Cobitis taenia Linnaeus, 1758, there were revealed several evolutionary and genetically discrete forms. Such variability was the basis for isolation or description of a record, for current systematics, number of species of European vertebrates, many of which can be considered twin species. Whereas seventy years ago in the whole Palearctic there swam only C. taenia (Berg, 1949), the early millennium already sees dozens of species in the area (Perdices et al., 2016; Fish base).

Secondly, the loaches are capable of intense interspecific hybridization leading to di-, tri- and tetraploid hybrids as has been known since 1970s (Ueno, Ojima, 1976; Ueno et al., 1980; Vasil'ev, 1985). It has been established since then that in most European polyploid biotypes' chromosome sets, there are one or two genomes of C. elongatoides Bacescu, Mayer, 1969 (Bohlen, Rab, 2001; Bohlen et al., 2002; Boroń, 2003; Culing et al., 2006; Mezhzherin, Pavlenko, 2010), which lives in the Danube drainage basin and in the upper reaches of the Rhine and Oder. The genomes of genetically similar C. taenia and C. tanaitica Bacescu, Mayer, 1969 also contribute to polyploids. The range of C. taenia occupies the basins of Dniester, Southern Buh, Dnipro, and Don, and reaches the Volga and also the rivers of the North and Baltic Seas. In the upper reaches of the Rhine and Oder the species hybridizes with C. elongatoides (Boroń, 2003; Culing et al., 2006). The range of C. tanaitica lies more to the south and covers Lower Danube, lower reaches of Southern Bug and Dnipro, rivers of the Azov Sea, including Don (Vasil'ev, Vasil'eva, 1998). The hybridization between C. taenia and C. tanaitica does not directly result in allotriploids since polyploids with only these species' genomes are so far unknown (Bohlen, Rab, 2001; Culing et al., 2006; Mezhzherin, Pavlenko, 2009). The wide area of genetic introgressions between these species includes the Lower Dnipro and Seversky Donets river system (Mezhzherin, Pavlenko, 2009), as well as the Southern Bug (Bohlen, Rab, 2001). In triploid loaches, the most frequent genome combinations are as follows: one C. elongatoides and two C. tanaitica (biotype C. elongatoides-2 tanaitica), one C. elongatoides and two C. taenia (biotype C. elongatoides-2 taenia), one C. elongatoides combined with genomes of C. taenia and C. tanaitica (biotype C. elongatoides-tanaitica-taenia) and two genomes of C. elongatoides combined with genome of C. tanaitica (biotype C. 2 elongatoides-tanaitica). Much more seldom, in Ukrainian rivers there occur triploids having genomes of Sabanejewia aurata (De Filippi, 1863) and genomes of C. taenia and C. tanaitica (biotype C. taenia-C. tanaitica-S. aurata) (Mezhzherin et al., 2014). Tetraploids' genomic structure is much more diverse, yet such biotypes are found significantly more seldom than triploids. Gametogenesis in hybrids is done by abnormal meiosis, and reproduction is mostly through gynogenesis, since in diploids always, and in triploids sometimes, there occurs fertilization which leads to tri- and tetraploids, respectively. Evidently, the presence of specimens with intermediate in regards to the parent species' phenotypes, creates large problems in practical species diagnostics, moreover in a taxonomical group where interspecies variability of morphometric parameters might be cryptic.

An explicit study of various exterior parameters in parental species and hybrid genotypes in Polish waters (Kotusz, 2000, 2008) showed that not only different hybrid biotypes but even the parental species cannot be distinguished with certainty based on such body measurements. Moreover, there was no clear logic of morphological differentiation which should be apparent in a situation where polyploid forms show gene dosage effect.

Morphometric parameters, despite being of limited use in systematics of the genus Cobitis, retain a significant place in taxonomic analysis. For descriptions of new species, body measurements are still an important part of species diagnostics (Vasil'eva, Vasil'ev, 2012; Chen et al., 2015; Mousavi-Sabet et al., 2015)

With this in mind, and seeing that the previous research was limited only to Polish populations, we consider studying morphometric variability of the parental species and hybrid forms an urgent task, made more relevant by sampling fishes from different river basins, with different ratios of the parental species and hybrid biotypes.

\section{Material and methods}

Our study was based on series of loaches caught in Ukrainian waters: 1 - Lower Danube $(45.39,29.59)$, 2 - Trans Carpathian rivers, left tributaries of Tisza (48.15, 23.39), 3 - Lower Dnipro (46.60, 32.59), 4 Sobok River, secondary tributary of the Southern Buh (49.11,29.03), 5 - lake Babye, Middle Dnipro floodplain (50.47, 30.54), 6 - Irpin River, right tributary of Middle Dnipro (50.52, 30.26), 7 - Navaria, water reservoir on the Shchirets River, left tributary of Dniester (49.74, 23.95), 8 - Styr River, tributary of Pripyat River (50.74, 25.31) (fig. 1). The total number of fishes was 819 . 


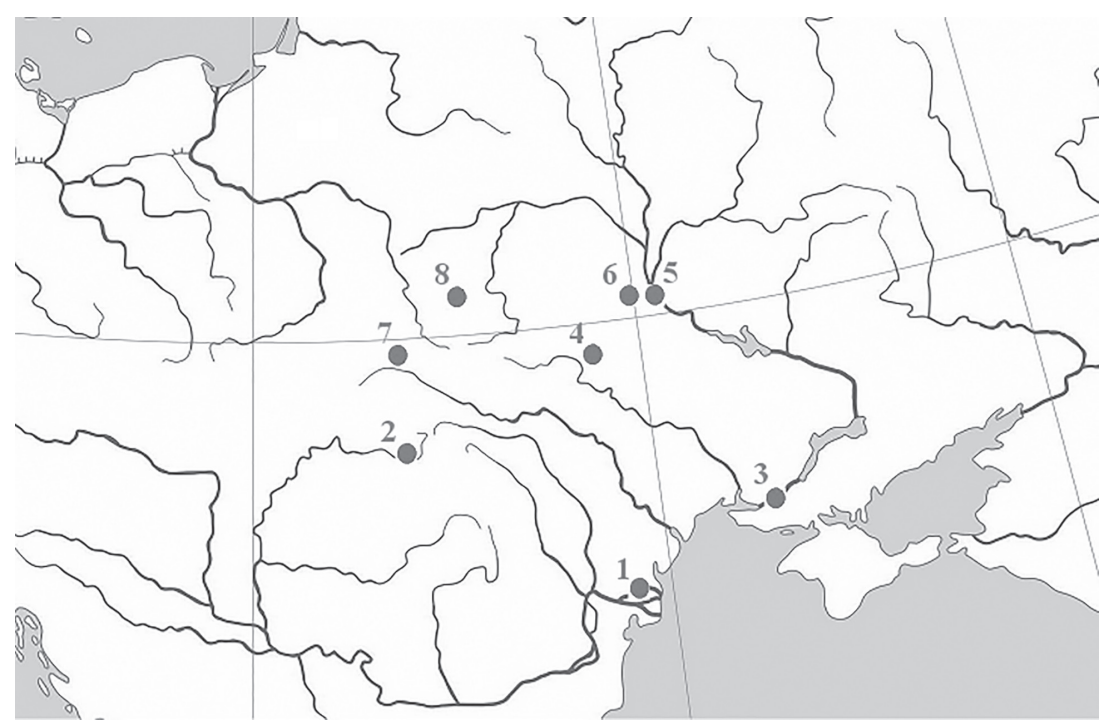

Fig. 1. Collection points of spined loaches in the river systems of Ukraine. The decoding of the numbering of samples is given in Material and methods.

Every fish was genetically tested by electrophoretic analysis of three enzymes and structural proteins of its muscle. The following loci were studied: Aat-1 (codes the soluble form of aspartatamino transferase), Mdh-1 (codes the soluble form of malate dehydrogenase), $L d h$-B (codes a heart subunit of lactate dehydrogenase) and Pt-3 (codes one of the soluble muscle proteins). Electrophoresis was carried out in SDS-PAGE in Tris-Glycine system (Peacock et al., 1965). We also did a cytometric analysis by measuring erythrocyte area (Sezaki et al., 1977). The material was then divided into biotypes, and every specimen classified according to the grouping.

Sex was determined by the presence or absence of the Canestrini's organ - the thickening of the first ray of the pectoral fin, characteristic of males of every species in C. taenia.

The morphometric analysis was done according to the standard plan adapted to cobitids (Pravdin, 1966). We measured 23 body parameters (fig. 2): $L-$ total length, $S L-$ standard length, $C L-$ corpus length, ao - snout length, $o$ - eye diameter, $c-$ head length, po - postorbital length, $h c-$ head height, $H$ - depth of body at the deepest point, $h$ - depth of body at the smallest point, $a D$ - antidorsal length, $p D-$ postdorsal length, $a V$ - antiventral length, $a A-$ antianal length, $l D$ - length of dorsal fin, $h D-$ height of dorsal fin, $l A$ - length of anal fin, $h A$ - height of anal fin, $l P$ - length of pectoral fin, $l V$ - pelvic fin length, $P V$ - distance between pectoral and pelvic fin, VA - distance between dorsal and anal fin, $l c a u d v$ - caudal peduncle length. Variability analysis was done using indices, for which the measurements were taken as $\%$ of corpus length. All fishes were fixed in $4 \%$ formaldehyde and measured by the same person.

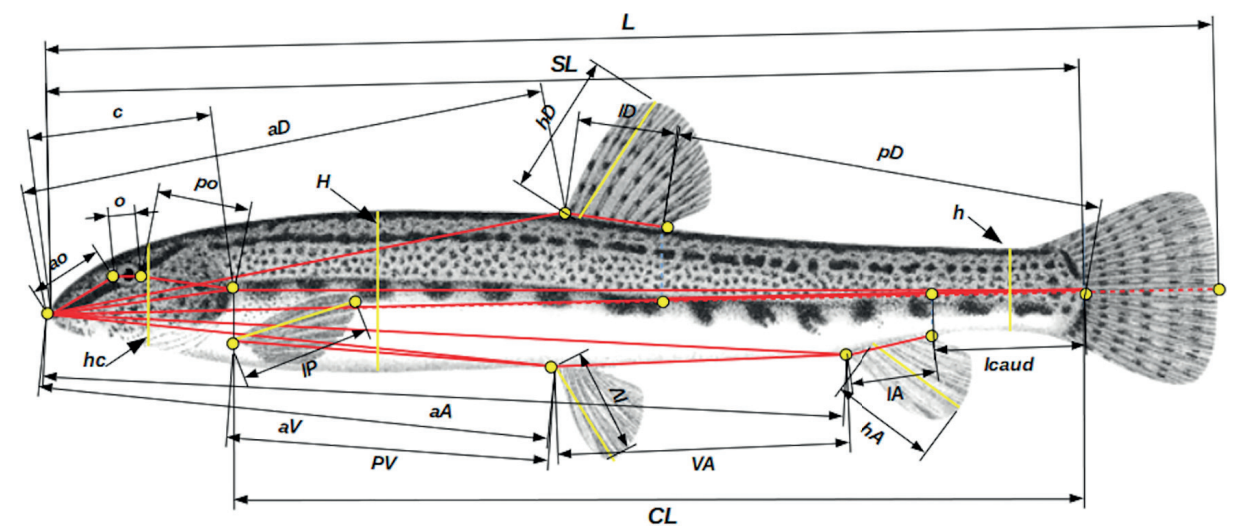

Fig. 2. Body measurements for Cobitis. The original fish image is from Wilhelm von Wright out of Fries, 1895. 
In total, 49 variables were taken into account: 23 absolute measurements and 26 indices. Most indices were ratios of various body measurements to corpus length. Besides that, we also used five other indices $(a o / c$, $o / c, i o / c, l c a u d / a D, l c a u d / h c)$.

The number of variables was close to the number of samples in some groups which can cause statistical artifacts of significant separation of the groups (Mitteroecker, Bookstein, 2011). Thus, classification and group separation was conducted with between-group PCA implemented in function group PCA of R (version 3.4.2; R Core Team, 2017) package Morpho (version 2.5.1; Schlager, 2017). It projects data onto orthogonal axes of group means variation and tests pairwise between-group differences with the permutation test (we used 10000 iterations). Measurements and indices were taken at different scales; some of the variables ( $L, S L, C L, a A, l c a u d /$ $h c$ ) had high variances. So, $\log 10$-transformation was applied in order to stabilize the variance.

Differences in biotypes were estimated with permutational ANOVA test implemented in the function aovp of package lmPerm v. 2.1.0 (Wheeler and Torchiano, 2016) and permutational multivariate analysis of variance (PERMANOVA) with Euclidean distance measure and 1000 permutations implemented in the function adonis of package vegan v. 2.5-3 (Oksanen et al., 2018). Mahalanobis distances were estimated as Euclidean distances between group means of the canonical variates (function CVA of the package Morpho). Bootstrap support for the hierarchical clustering was evaluated with package pvclust v. 2.0-0 (Suzuki, Shimodaira, 2015).

\section{Results}

Biotype identification and population structure determination. In order to do this, we used a set of four loci and cytometry data which allowed us to assign biotypes and species and separate the loaches into ten groups (table 1).

The spined loach C. taenia (TT) in Ukraine is genetically heterogeneous (Mezhzherin, Pavlenko, 2009), which is caused by massive introgressive hybridization with C. tanaitica and by gene flows, in particular, alleles of locus $L d h$-B. The Lower Dnipro is an area of in-

Table 1. Electromorph types for four loci in different groups of the hybrid biotypes and species of Cobitis

\begin{tabular}{|c|c|c|c|c|}
\hline \multirow{2}{*}{ Species and biotypes } & \multicolumn{4}{|c|}{ Loci genotypes } \\
\hline & Aat-1 & $M d h-1$ & $L d h-\mathrm{B}$ & $P t-3$ \\
\hline $\begin{array}{l}\text { TT } \\
\text { C. taenia }\end{array}$ & $100-100$ & $100-100$ & $\begin{array}{l}100-100 \\
100-105 \\
105-105\end{array}$ & $100-100$ \\
\hline $\begin{array}{l}\text { NN } \\
\text { C. tanaitica }\end{array}$ & $100-100$ & $\begin{array}{l}100-100 \\
100-110 \\
110-110\end{array}$ & $100-100$ & $90-90$ \\
\hline $\begin{array}{l}\text { EE } \\
\text { C. elongatoides }\end{array}$ & $\begin{array}{l}105-105 \\
105-110 \\
110-110\end{array}$ & $110-110$ & $100-100$ & $90-90$ \\
\hline $\begin{array}{l}\text { EN } \\
\text { C. elongatoides-tanaitica }\end{array}$ & $100-110$ & $\begin{array}{l}100-110 \\
110-110\end{array}$ & $100-100$ & $90-90$ \\
\hline $\begin{array}{l}\mathrm{ENN}(\mathrm{N}) \\
\text { C. elongatoides-2 (3) tanaitica }\end{array}$ & $100-100-110$ & $\begin{array}{l}100-100-110 \\
100-110-110 \\
110-110-110\end{array}$ & $100-100$ & $90-90-90$ \\
\hline $\begin{array}{l}\text { ENT(NT) } \\
\text { C. elongatoides-2 (3) taenia; } \\
\text { C. elongatoides-1 (2) taenia-1 (2) tanaitica }\end{array}$ & $100-100-110$ & $100-100-110$ & $\begin{array}{l}100-100-100 \\
100-100-105 \\
100-105-105\end{array}$ & $\begin{array}{l}90-90-100 \\
90-100-100\end{array}$ \\
\hline $\begin{array}{l}\mathrm{EE}(\mathrm{E}) \mathrm{N} \\
\text { C. } 2 \text { (3) elongatoides-tanaitica }\end{array}$ & $\begin{array}{l}100-105-105 \\
100-105-110 \\
100-110-100\end{array}$ & $\begin{array}{l}100-110-110 \\
100-105-110 \\
100-110-100\end{array}$ & $100-100-100$ & $90-90-90$ \\
\hline $\begin{array}{l}\text { EEN }{ }^{95} \\
\text { C. } 2 \text { (3) elongatoides-tanaitica }{ }^{95}\end{array}$ & $95-100-110-110$ & $100-110-110$ & $100-100-100$ & $90-90-90$ \\
\hline $\begin{array}{l}\text { EEN }^{95} \mathrm{~T} \\
\text { C. } 2 \text { (3) elongatoides-taenia-tanaitica }\end{array}$ & $95-100-110-110$ & $100-100-110-110$ & $100-100-100-100$ & $90-90-90-100$ \\
\hline $\begin{array}{l}\text { ANT } \\
\text { C. taenia-C. tanaitica-Sabanejewia aurata }\end{array}$ & $100-100 / 110$ & $100-100 / 110$ & $90 / 100-100$ & - \\
\hline
\end{tabular}


trogressive hybridization between C. taenia. Specimens from the region hads lightly more than half of allele genes specific for C. taenia, which lets us to formally assign them to the species. In the Navaria population of diploid C. taenia there was found a unique allelomorph $L d h-\mathrm{B}^{105}$, which shows its evolutionary isolation from other populations. In the populations of the Middle Dnipro basin there were no genes specific for C. tanaitica, and $L d h-\mathrm{B}^{105}$ was infrequent. This could be viewed to support the species's relative homogeneity in the region. Genetically homogeneous C. tanaitica (NN) was found only in the Lower Danube basin. C. elongatoides (EE) was caught in Lower Danube but also in the Trans Carpathian Tisza tributaries.

The biotypical structure of the samples is presented in table 2. In the Lower Danube basin the rewere found diploid hybrids C. elongatoides-tanaitica (biotype EN), triploid C. elongatoides -2 tanaitica and very rare tetraploids C. elongatoides -3 tanaitica. The latter two biotypes here are combined $(\mathrm{ENN}(\mathrm{N}))$. The most frequent in the Lower Danube basin were triploid hybrids (C. 2 elongatoides-tanaitica), also found in the Tisza basin. Tetraploids (C. 3 elongatoides-tanaitica) were very scarce and so are analyzed together with triploids (C. 2 elongatoides-tanaitica) as the biotype groupe $\mathrm{EE}(\mathrm{E}) \mathrm{N}$. Triploids in whose chromosome sets were two genomes of $C$. elongatoides and one of $C$. tanaitica, also were the most abundant in the Irpin River basin. However, here they were genetically unstable, which can be seen in the disrupted structure of the electrophoresis of certain enzymes (Mezhzherin, Pavlenko, 2007). They were assigned a distinct biotype $\left(\mathrm{EEN}^{95}\right)$. In the Irpin basin we also found tetraploid C. 2 elongatoides-taenia-tanaitica $a^{95}$, separated into biotype EENN ${ }^{95}$.

Five biotypes were grouped together as ENT(NT); their chromosome sets included one genome of C. elongatoides and always one or two genomes of C. taenia (C. elongatoides2 taenia, C. elongatoides-taenia-tanaitica, C. elongatoides-3 taenia, C. elongatoides-2 taenia-tanaitica, C. elongatoides-taenia-2 tanaitica). The reason for their merging was, first of all, insufficient resolution of electrophoresis to distinguish between C. taenia and C. tanaitica. The only currently known locus which allows distinguishing them, $P t-3$, has low expression levels during summer, and when its products are poorly presented on electrophoregrams, it becomes impossible to set apart biotypes with and without $C$. tanaitica genome.

Another triploid biotype, C. taenia-C. tanaitica-Sabanejewia aurata (ATN), has instead of the genome of C. elongatoides the chromosomes of Sabanejewia aurata (Mezhzherin et al., 2014).

Sex structure and dimorphism. As expected, almost all hybrid biotype specimens were female (table 3). The scarce males were found for $\mathrm{ENN}(\mathrm{N})$ and $\mathrm{EEN}^{95}$, making up $1.4 \%$ and $0.8 \%$ of the biotypes, respectively, and in ANT males were even more frequent $-14.2 \%$. In diploid species males were also in minority. In C. taenia and C. elonga-

Table 2. Species and biotypes structure of spined loaches' populations

\begin{tabular}{l|c|c|c|c|c|c|c|c|c|c}
\hline \multicolumn{1}{c}{ Population } & TT & NN & EE & EN & ENT(NT) & ENN(N) & EE(E)N & EEN $^{95}$ & EEN $^{95}$ T & ANT \\
\hline Lower Danube & & 8 & 21 & 15 & & 70 & 237 & & & \\
Tisza Basin & & & 34 & & & & 6 & & & \\
Lower Dnipro & 25 & & & & & & 8 & & & \\
Sobok & 38 & & & & & & & & & 6 \\
Lake Babye & 17 & & & 19 & & & & & \\
Irpin & 21 & & & 37 & & & 122 & 8 & \\
Navaria & 60 & & & 8 & & & & & \\
Styr & 4 & & & 45 & & 1 & & & 8 \\
\hline
\end{tabular}

Note. Biotype designations are explained in table 1. 
Table 3. Sex ratios in spined loaches by species and biotypes

\begin{tabular}{lccc}
\hline \multicolumn{1}{c|}{ Biotypes } & ᄋ & $\sigma^{\top}$ \\
\hline TT & 108 & 57 \\
EE & 35 & 20 \\
NN & 8 & 0 \\
EN & 15 & 0 \\
ENT(NT) & 108 & 0 \\
ENN(N) & 69 & 1 \\
EE(E)N & 252 & 0 \\
EE ${ }^{95}$ & 121 & 1 \\
EEN $^{95} \mathrm{~T}$ & 8 & 0 \\
ANT & 12 & 2 \\
\hline
\end{tabular}
table 1 .

Note. Biotype names are explained in

Variability of morphological parameters. Most of the between-biotypes variation of absolute traits can be explained with one between-group principal component (bg-PC1). It described $97.1 \%$ of variation and was associated with the unidirectional change of all traits (table 5). The second component explained only $1.3 \%$ of the total variability.

The distributions of some biotypes and species in the space of the first two components overlapped to a large extent (fig. 3). Overall classification by absolute traits was $40.7 \%$. A similar situation is observed for the third and fourth components (fig. 4).

Most of the between-group differences in indices were explained with four principal components (table 6), which explained $93.6 \%$ of total variability. The main variation was mostly associated with head indices (bgPC1: ao/CL, $h c / C L, c / C L, o / C L$ ) and relative size of fins (bgPC2: $l V / C L, h A / C L, l P / C L$ ). All biotypes were overlapping in space of principal components (fig. 5). In total, only $28.2 \%$ of specimens were correctly classified.

Discrimination and diagnostics of Cobitis using body measurements and indices. Analysis of both absolute measurements and indices showed that the grouping factor does have an effect (ANOVA, $\mathrm{p}<0.001)$ on the variability of all traits except $l A / C L$, $V A / C L$, lcaud/CL (ANOVA, $\mathrm{p}>0.01$ ). However, due to significant transgression not a single trait (index) could be used in practice as a diagnostic tool to distinguish species and biotypes.

Table 4. Total length and body indices showed to be important for group-PCA. Intersex differences were significant (ANOVA, p $<0.01$ )

\begin{tabular}{l|c|c|c|c|c|c|c|c}
\hline \multirow{2}{*}{ Parameters } & \multicolumn{4}{c|}{ C. taenia } & \multicolumn{4}{c}{ C. elongatoides } \\
\cline { 2 - 9 } & \multicolumn{2}{c|}{$\begin{array}{c}\text { males } \\
\mathrm{N}=57\end{array}$} & \multicolumn{2}{c|}{$\begin{array}{c}\text { females } \\
\mathrm{N}=108\end{array}$} & \multicolumn{2}{c}{$\begin{array}{c}\text { males } \\
\mathrm{N}=20\end{array}$} & \multicolumn{2}{c}{$\begin{array}{c}\text { females } \\
\mathrm{N}=35\end{array}$} \\
\cline { 2 - 9 } & $\mathrm{M}$ & $\mathrm{SD}$ & $\mathrm{M}$ & $\mathrm{SD}$ & $\mathrm{M}$ & $\mathrm{SD}$ & $\mathrm{M}$ & $\mathrm{SD}$ \\
\hline $\mathrm{L}, \mathrm{mm}$ & 65.4 & 6.6 & 77.1 & 11.9 & 65.4 & 8.9 & 77.4 & 17.0 \\
$\mathrm{lP} / \mathrm{CL}$ & 0.198 & 0.030 & 0.148 & 0.021 & 0.201 & 0.023 & 0.149 & 0.014 \\
$\mathrm{lV} / \mathrm{CL}$ & 0.155 & 0.023 & 0.140 & 0.014 & 0.170 & 0.019 & 0.143 & 0.012 \\
$\mathrm{lA} / \mathrm{CL}$ & 0.087 & 0.015 & 0.079 & 0.011 & 0.094 & 0.018 & 0.080 & 0.009 \\
$\mathrm{hA} / \mathrm{CL}$ & 0.169 & 0.025 & 0.150 & 0.015 & 0.179 & 0.020 & 0.157 & 0.014 \\
\hline
\end{tabular}

Note. $\mathrm{N}$ - sample size, $\mathrm{M}$ - mean, $\mathrm{SD}$ - standard deviation. 
Multivariate analysis of differences using aggregated traitsin samples which had mostspecimens showed statistically significant heterogeneity (PERMANOVA: Danube, $\mathrm{F}=11.3 \mathrm{df}=(4,339)$, $\mathrm{p}<0.001$; Irpin, $\mathrm{F}=4.0, \mathrm{df}=(3,145), \mathrm{p}=0.003)$. Yet the factor of assigned biotype explained only a small part of the total variability: Danube partial $\mathrm{R}^{2}=11.8 \%$, Irpin partial $\mathrm{R}^{2}=7.7 \%$. Classification in the samples was also unsatisfactory. According to between-group PCA, Danube biotypes were classified correctly in $54 \%$ cases, and the best identified biotypes were $\mathrm{EE}(9$ out of $15,60 \%)$ and $\mathrm{EE}(\mathrm{E}) \mathrm{N}$ (149 out of 239, $62.3 \%)$. In Irpin the total classification accuracy was $49 \%$, and the best classified was biotype ENT(NT) ( 21 out of $30,70 \%$ ).

As to the whole aggregate of traits, biotypes also did not differ strongly - overall classification accuracy was $54 \%$, although between-group differences were statistically significant: PERMANOVA: $\mathrm{F}=23.8, \mathrm{df}=(9,725), \mathrm{p}<0.001$.

Excluding hybrid biotypes did not result in better classification. Between-group PCA allowed true identification of $35 \%$ specimens. Interspecies differences by all traits were not statistically significant, PERMANOVA: $\mathrm{F}=1.7, \mathrm{df}=(2,148), \mathrm{p}=0.132$. Onedimensional analysis showed statistically significant differences in two traits describing the dorsal fin (ID/ $C L, h D / C L$; ANOVA, $\mathrm{p}<0.001)$, and the species' ranges significantly transgressed (table 7 ).
Table 5. Loadings of the between-group principal components calculated for absolute traits to separate biotypes

\begin{tabular}{l|cc|}
\hline \multicolumn{1}{c|}{ Variable } & bgPC1 & bgPC2 \\
\hline Explained variance, \% & 97.09 & 1.32 \\
$L$ & -0.191 & -0.083 \\
$S L$ & -0.190 & -0.132 \\
$C L$ & -0.202 & -0.178 \\
$a o$ & -0.216 & 0.491 \\
$o$ & -0.220 & 0.213 \\
$c$ & -0.213 & 0.111 \\
$p o$ & -0.233 & 0.175 \\
$h c$ & -0.227 & -0.055 \\
$H$ & -0.263 & -0.020 \\
$h$ & -0.274 & 0.080 \\
$a D$ & -0.190 & -0.208 \\
$p D$ & -0.208 & 0.007 \\
$a V$ & -0.213 & -0.166 \\
$a A$ & -0.214 & -0.153 \\
$l D$ & -0.220 & 0.038 \\
$h D$ & -0.202 & 0.210 \\
$l A$ & -0.194 & 0.049 \\
$h A$ & -0.164 & 0.173 \\
$l P$ & -0.172 & 0.185 \\
$l V$ & -0.147 & 0.209 \\
$P V$ & -0.193 & -0.494 \\
$V A$ & -0.214 & -0.195 \\
$l c a u d$ & -0.193 & -0.271 \\
\hline & & \\
\hline
\end{tabular}

Note.bgPC - between-group principal component.

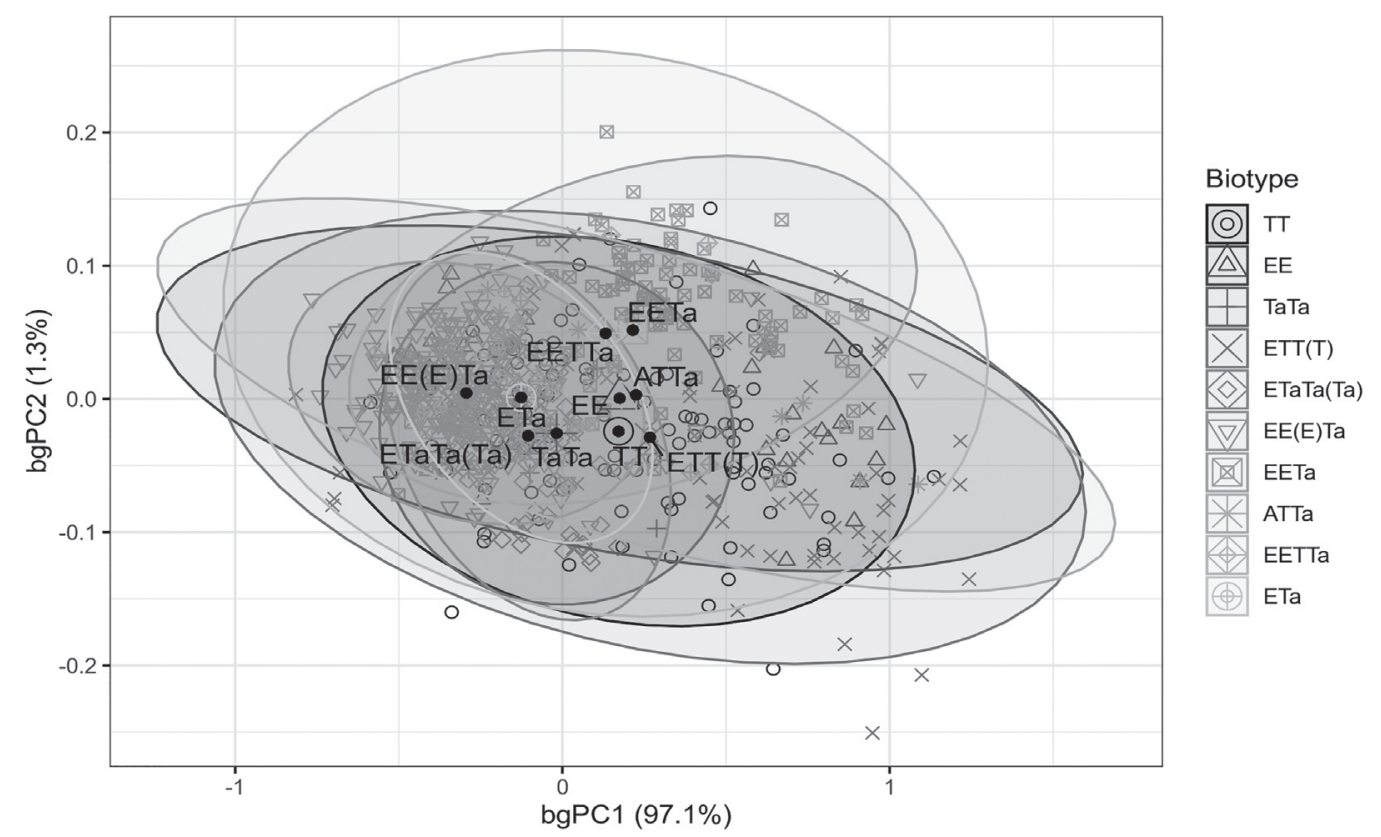

Fig. 3. $95 \%$ confidence interval ellipses of the biotypes in the morphospace of bgPC1 and bgPC2 calculated for $\log 10$-transformed absolute traits. Each biotype means are marked with black points and names. The biotypes are explained in table 1. 
Table 6. Loadings of the between-group principal components calculated for indices

\begin{tabular}{|c|c|c|c|c|}
\hline Index & bg-PC1 & bg-PC2 & bg-PC3 & bg-PC4 \\
\hline Explained variance, $\%$ & 41.08 & 25.87 & 16.43 & 10.23 \\
\hline$L / C L$ & -0.045 & -0.107 & -0.006 & 0.005 \\
\hline$S L / C L$ & -0.012 & -0.107 & -0.014 & 0.046 \\
\hline$a o / C L$ & -0.438 & -0.109 & 0.220 & 0.030 \\
\hline$o / C L$ & -0.371 & -0.059 & -0.579 & -0.076 \\
\hline$c / C L$ & -0.231 & -0.029 & -0.043 & 0.114 \\
\hline po/CL & -0.277 & 0.110 & 0.175 & 0.068 \\
\hline$h c / C L$ & -0.146 & 0.133 & -0.062 & -0.011 \\
\hline$H / C L$ & -0.256 & 0.340 & -0.025 & 0.243 \\
\hline$h / C L$ & -0.303 & 0.455 & 0.111 & -0.126 \\
\hline$a D / C L$ & 0.022 & -0.073 & -0.102 & 0.019 \\
\hline$p D / C L$ & -0.096 & 0.039 & 0.147 & -0.302 \\
\hline$a V / C L$ & -0.061 & 0.049 & -0.099 & 0.181 \\
\hline$a A / C L$ & -0.057 & 0.079 & -0.060 & 0.018 \\
\hline$l D / C L$ & -0.211 & -0.034 & 0.050 & 0.626 \\
\hline$h D / C L$ & -0.229 & -0.116 & 0.218 & 0.003 \\
\hline$l A / C L$ & -0.159 & -0.159 & -0.045 & 0.218 \\
\hline$h A / C L$ & -0.125 & -0.330 & 0.171 & -0.206 \\
\hline$l P / C L$ & -0.189 & -0.349 & -0.069 & 0.026 \\
\hline$l V / C L$ & -0.144 & -0.509 & -0.010 & -0.072 \\
\hline$P V / C L$ & 0.166 & -0.017 & -0.238 & 0.349 \\
\hline$V A / C L$ & -0.022 & 0.107 & -0.073 & -0.150 \\
\hline lcaud/CL & 0.077 & -0.067 & 0.009 & 0.184 \\
\hline$a o / c$ & -0.207 & -0.079 & 0.263 & -0.084 \\
\hline$o / c$ & -0.140 & -0.029 & -0.536 & -0.191 \\
\hline lcaud/aD & 0.055 & 0.006 & 0.111 & 0.165 \\
\hline lcaud/hc & 0.223 & -0.200 & 0.071 & 0.195 \\
\hline
\end{tabular}
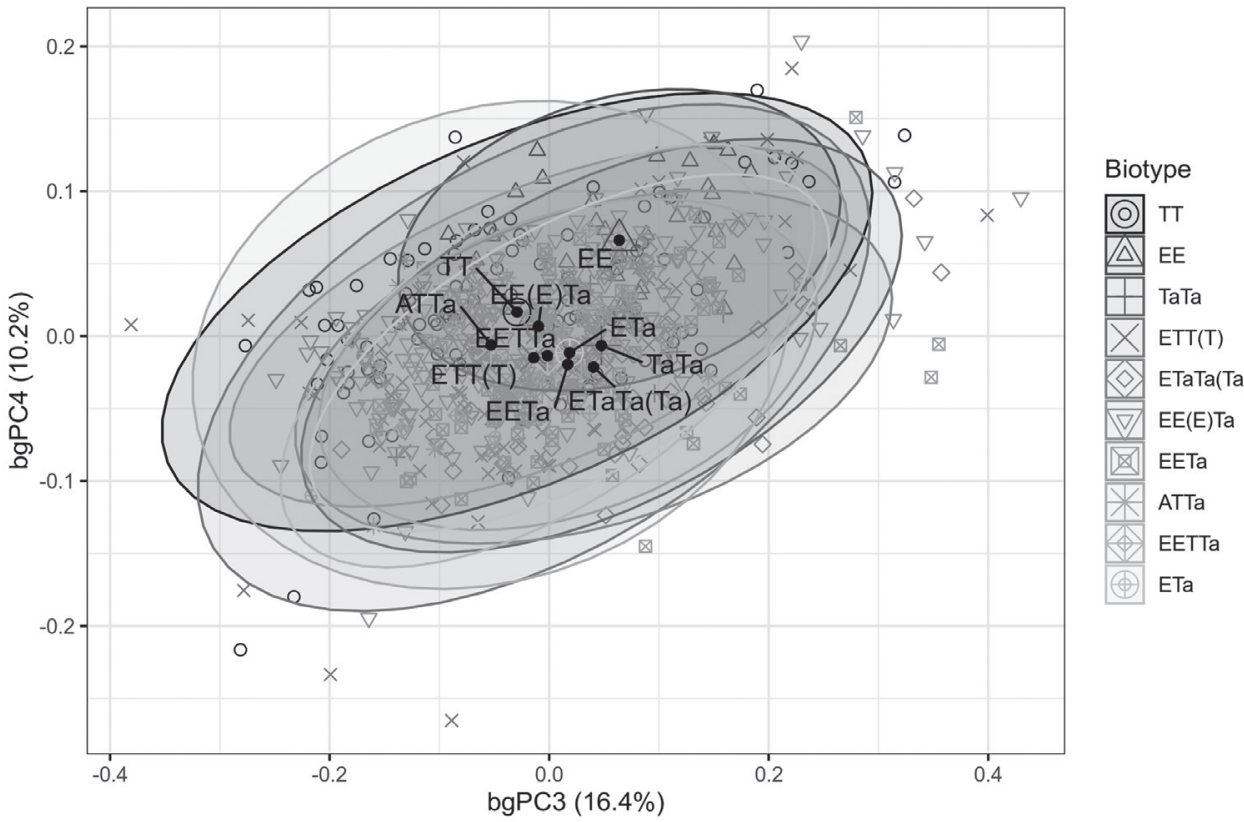

Fig. 4. 95\% confidence interval ellipses of the biotypes in the morphospace of bg PC3 and bgPC4 calfulated for $\log 10$ transformed absolute traits. Designations the same as on fig. 3. 


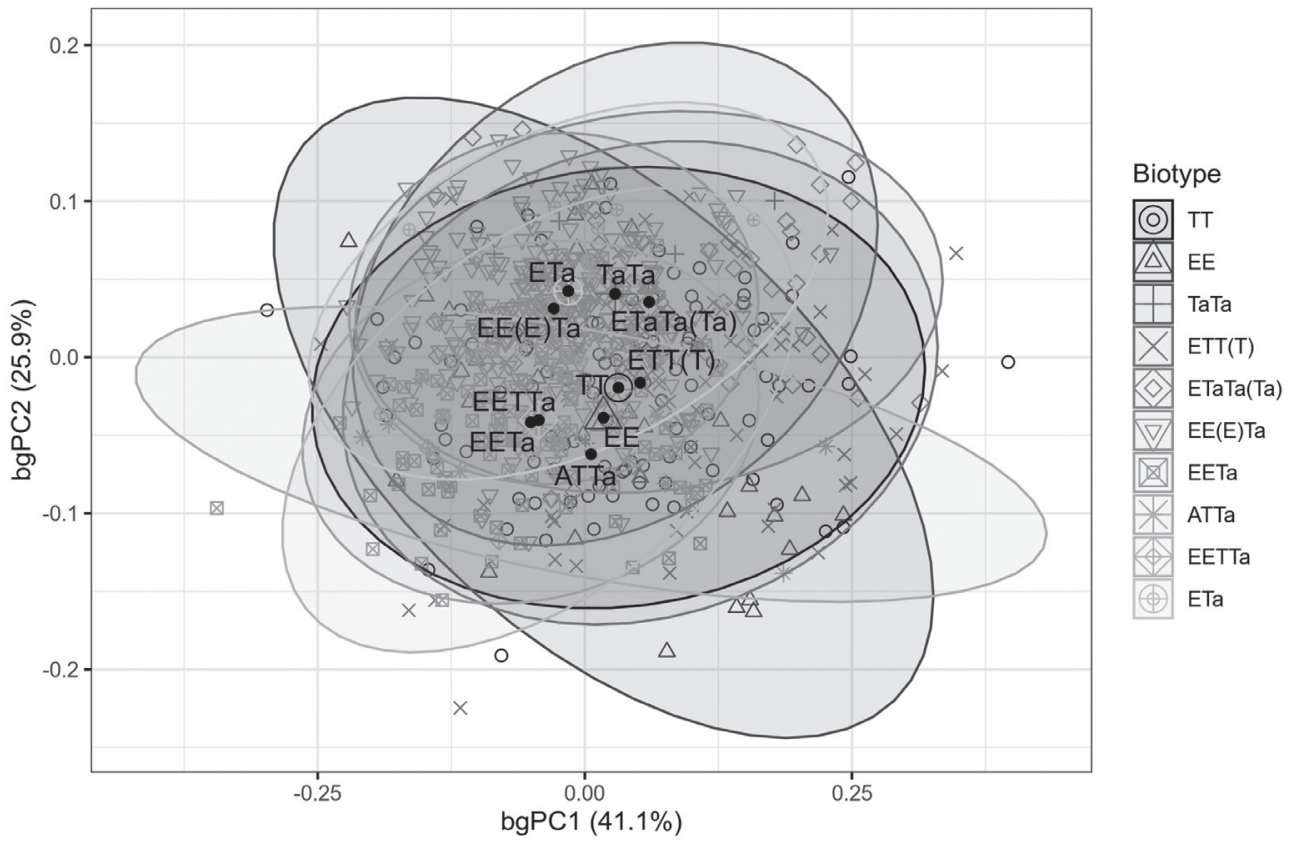

Fig $5.95 \%$ confidence ellipses of the biotypes in the morphospace of four between-group principal components calculated for indices. Mean groups of each biotype is marked with black point and designation.

If hybrids alone were analyzed, classification was true for $54 \%$ specimens. Intergroup differences using aggregated traits were statistically significant, PERMANOVA: $\mathrm{F}=32.9$, $\mathrm{df}=(6,577), \mathrm{p}<0.001$.

Morphological remoteness of biotypes and species

According to pair wise comparisons of biotypes (PERMANOVA), both body measurements and indices showed significant differences: 19 out of 45 measurement tests and 23 out of 45 indices (table 8). For 14 pairs the differences were statistically significant in both cases. Yet the link between biotype and trait was not strong; partial $\mathrm{R}^{2}$ ranged from 0.2 to $36.3 \%$ (table 10 ).

Between-group remoteness was estimated by Mahalanobis distances (table 9). For both measurements and indices, the Mahalanobis distances were small: the amplitude was 1.15-3.49 in the terms of standard deviations. Approximately unbiased bootstrap p-values

Table 7. Mean values, standard deviation and ranges of some body measurements and indices

\begin{tabular}{|c|c|c|c|c|c|c|c|c|c|}
\hline \multirow{2}{*}{ Trait } & \multicolumn{3}{|c|}{$\begin{array}{l}\text { C. elongatoides } \\
\quad \mathrm{N}=35\end{array}$} & \multicolumn{3}{|c|}{$\begin{array}{l}\text { C. taenia } \\
\mathrm{N}=108\end{array}$} & \multicolumn{3}{|c|}{$\begin{array}{l}\text { C. tanaitica } \\
\quad N=8\end{array}$} \\
\hline & M & SD & Min-Max & M & SD & Min-Max & $\mathrm{M}$ & SD & Min-Max \\
\hline $\mathrm{Ld} / \mathrm{CL}$ & 0.110 & 0.010 & $0.091-0.131$ & 0.101 & 0.012 & $0.057-0.130$ & 0.098 & 0.008 & $0.086-0.111$ \\
\hline $\mathrm{hD} / \mathrm{CL}$ & 0.198 & 0.014 & $0.144-0.226$ & 0.183 & 0.020 & $0.108-0.235$ & 0.192 & 0.013 & $0.171-0.214$ \\
\hline $\mathrm{pD} / \mathrm{CL}$ & 0.448 & 0.038 & $0.350-0.508$ & 0.451 & 0.028 & $0.368-0.517$ & 0.488 & 0.017 & $0.468-0.518$ \\
\hline $\mathrm{Ao} / \mathrm{c}$ & 0.436 & 0.042 & $0.357-0.517$ & 0.410 & 0.035 & $0.321-0.500$ & 0.412 & 0.041 & $0.348-0.464$ \\
\hline $\mathrm{pD}, \mathrm{mm}$ & 25.1 & 4.4 & $14-36$ & 24.9 & 6.9 & $16-37$ & 29.1 & 2.2 & $26-33$ \\
\hline $\mathrm{CL}, \mathrm{mm}$ & 55.4 & 8.8 & $39-77$ & 55.3 & 12.7 & $35-76$ & 59.8 & 5.4 & $54-70$ \\
\hline
\end{tabular}

Note. $\mathrm{N}$ - sample size, $\mathrm{M}$ - mean, $\mathrm{SD}$ - standard deviation, Min — minimum, Max — maximum. 
Table 8. Results of the pairwise PERMANOVA

\begin{tabular}{|c|c|c|c|c|c|c|c|}
\hline \multirow{2}{*}{ Pair of groups } & \multirow{2}{*}{$\mathrm{df} 2$} & \multicolumn{3}{|c|}{ Measurements } & \multicolumn{3}{|c|}{ Indices } \\
\hline & & $\mathrm{F}(1, \mathrm{df} 2)$ & $\mathrm{p}$ & Partial R², \% & $F(1, d f 2)$ & $\mathrm{p}$ & Partial R ${ }^{2}, \%$ \\
\hline TT vs. EE & 141 & 0.96 & 0.326 & 0.7 & 4.91 & 0.001 & 3.4 \\
\hline TT vs. NN & 114 & 1.95 & 0.139 & 1.7 & 1.31 & 0.222 & 1.1 \\
\hline TT vs. ENT(NT) & 214 & 2.37 & 0.103 & 1.1 & 1.71 & 0.110 & 0.8 \\
\hline TT vs. ENN(N) & 175 & 26.41 & 0.001 & 13.1 & 6.85 & 0.001 & 3.8 \\
\hline TT vs. $\mathrm{EE}(\mathrm{E}) \mathrm{N}$ & 358 & 156.97 & 0.001 & 30.5 & 10.06 & 0.001 & 2.7 \\
\hline TT vs. EEN ${ }^{95}$ & 227 & 3.21 & 0.034 & 1.4 & 10.3 & 0.001 & 4.3 \\
\hline TT vs. ANT & 117 & 0.46 & 0.590 & 0.4 & 1.34 & 0.231 & 1.1 \\
\hline TT vs. $\mathrm{EEN}^{95} \mathrm{~T}$ & 114 & 0.44 & 0.622 & 0.4 & 1.36 & 0.223 & 1.2 \\
\hline TT vs. EN & 121 & 7.71 & 0.009 & 6 & 2.08 & 0.058 & 1.7 \\
\hline EE vs. NN & 41 & 1.06 & 0.318 & 2.5 & 1.75 & 0.112 & 4.1 \\
\hline EE vs. ENT(NT) & 141 & 1.39 & 0.243 & 1 & 5.54 & 0.001 & 3.8 \\
\hline EE vs. ENN(N) & 102 & 13.2 & 0.001 & 11.5 & 6.85 & 0.001 & 6.3 \\
\hline EE vs. $\mathrm{EE}(\mathrm{E}) \mathrm{N}$ & 285 & 65.3 & 0.001 & 18.6 & 10.67 & 0.001 & 3.6 \\
\hline EE vs. EEN & 154 & 1.53 & 0.198 & 1 & 7.64 & 0.001 & 4.7 \\
\hline EE vs. ANT & 44 & 0.4 & 0.570 & 0.9 & 3.52 & 0.009 & 7.4 \\
\hline EE vs. EENT & 41 & 0.35 & 0.607 & 0.8 & 2.48 & 0.023 & 5.7 \\
\hline EE vs. EN & 48 & 4.14 & 0.042 & 7.9 & 3.56 & 0.006 & 6.9 \\
\hline NN vs. ENT(NT) & 114 & 2 & 0.151 & 1.7 & 0.97 & 0.408 & 0.8 \\
\hline NN vs. $\operatorname{ENN}(\mathrm{N})$ & 75 & 1.02 & 0.346 & 1.3 & 0.52 & 0.800 & 0.7 \\
\hline $\mathrm{NN}$ vs. $\mathrm{EE}(\mathrm{E}) \mathrm{N}$ & 258 & 8.46 & 0.004 & 3.2 & 1.48 & 0.176 & 0.6 \\
\hline NN vs. EEN & 127 & 3.19 & 0.055 & 2.4 & 2.36 & 0.029 & 1.8 \\
\hline NN vs. ANT & 17 & 1.74 & 0.193 & 9.3 & 2.34 & 0.035 & 12.1 \\
\hline NN vs. EENT & 14 & 1.3 & 0.261 & 8.5 & 2.17 & 0.042 & 13.4 \\
\hline NN vs. EN & 21 & 1.5 & 0.198 & 6.7 & 0.61 & 0.778 & 2.8 \\
\hline $\mathrm{ENT}(\mathrm{NT})$ vs. $\mathrm{ENN}(\mathrm{N})$ & 175 & 25.97 & 0.001 & 12.9 & 4.09 & 0.002 & 2.3 \\
\hline ENT(NT) vs. EE(E)N & 358 & 156.55 & 0.001 & 30.4 & 13.28 & 0.001 & 3.6 \\
\hline ENT(NT) vs. EEN & 227 & 2.26 & 0.113 & 1 & 11.45 & 0.001 & 4.8 \\
\hline ENT(NT) vs. ANT & 117 & 0.23 & 0.777 & 0.2 & 1.42 & 0.183 & 1.2 \\
\hline ENT(NT) vs. EENT & 114 & 0.65 & 0.462 & 0.6 & 1.63 & 0.106 & 1.4 \\
\hline ENT(NT) vs. EN & 121 & 6.89 & 0.008 & 5.4 & 1.94 & 0.064 & 1.6 \\
\hline $\mathrm{ENN}(\mathrm{N})$ vs. $\mathrm{EE}(\mathrm{E}) \mathrm{N}$ & 319 & 29.54 & 0.001 & 8.5 & 13.18 & 0.001 & 4 \\
\hline ENN(N) vs. EEN & 188 & 39.92 & 0.001 & 17.5 & 16.1 & 0.001 & 7.9 \\
\hline ENN(N) vs. ANT & 78 & 12.25 & 0.001 & 13.6 & 4.31 & 0.003 & 5.2 \\
\hline ENN(N) vs. EENT & 75 & 6.58 & 0.004 & 8.1 & 2.94 & 0.013 & 3.8 \\
\hline ENN(N) vs. EN & 82 & 0.7 & 0.586 & 0.9 & 2.08 & 0.065 & 2.5 \\
\hline $\mathrm{EE}(\mathrm{E}) \mathrm{N}$ vs. EEN & 371 & 211.49 & 0.001 & 36.3 & 12.58 & 0.001 & 3.3 \\
\hline $\mathrm{EE}(\mathrm{E}) \mathrm{N}$ vs. ANT & 261 & 34.32 & 0.001 & 11.6 & 3.66 & 0.009 & 1.4 \\
\hline EE(E)N vs. EENT & 258 & 18.45 & 0.001 & 6.7 & 1.8 & 0.098 & 0.7 \\
\hline $\mathrm{EE}(\mathrm{E}) \mathrm{N}$ vs. EN & 265 & 5.75 & 0.005 & 2.1 & 1.01 & 0.339 & 0.4 \\
\hline EEN vs. ANT & 130 & 0.48 & 0.597 & 0.4 & 2.65 & 0.009 & 2 \\
\hline EEN vs. EENT & 127 & 0.51 & 0.563 & 0.4 & 0.85 & 0.516 & 0.7 \\
\hline EEN vs. EN & 134 & 11.2 & 0.002 & 7.7 & 2.6 & 0.008 & 1.9 \\
\hline ANT vs. EENT & 17 & 0.34 & 0.622 & 2 & 1.07 & 0.367 & 5.9 \\
\hline ANT vs. EN & 24 & 5.6 & 0.012 & 18.9 & 3.02 & 0.013 & 11.2 \\
\hline EETN vs. EN & 21 & 4.3 & 0.029 & 17 & 2.06 & 0.052 & 9 \\
\hline
\end{tabular}


(AU-values) of the UPGMA clustering were high for EE(E)N and EN, EEN and EENT, TT and ENT(NT) clusters (fig. 6). There was no one-to-one mapping between morphologic distance and genetic remoteness. However, as expected, the most remote proved to be C. elongatoides and the hybrid of golden spined loach (ANT).

Table 9. Mahalanobis distances between biotypes

\begin{tabular}{|c|c|c|c|c|c|c|c|c|c|}
\hline \multicolumn{10}{|c|}{ Distances by log10-transformed raw traits } \\
\hline & TT & $\mathrm{EE}$ & $\mathrm{NN}$ & $\mathrm{ENT}(\mathrm{NT})$ & $\operatorname{ENN}(\mathrm{N})$ & & EEN & ANT & EENT \\
\hline $\mathrm{EE}$ & 2.00 & & & & & & & & \\
\hline $\mathrm{NN}$ & 2.66 & 3.35 & & & & & & & \\
\hline $\mathrm{ENT}(\mathrm{NT})$ & 1.24 & 2.25 & 2.32 & & & & & & \\
\hline $\operatorname{ENN}(\mathrm{N})$ & 2.29 & 3.04 & 1.44 & 1.94 & & & & & \\
\hline $\mathrm{EE}(\mathrm{E}) \mathrm{N}$ & 1.89 & 2.72 & 1.94 & 2.04 & 1.51 & & & & \\
\hline EEN & 2.15 & 2.25 & 2.42 & 1.90 & 2.33 & & & & \\
\hline ANT & 2.27 & 2.20 & 3.49 & 2.00 & 3.14 & & 2.40 & & \\
\hline EENT & 2.38 & 2.60 & 2.63 & 2.36 & 2.46 & & 1.38 & 2.95 & \\
\hline EN & 2.19 & 2.98 & 1.87 & 1.97 & 1.52 & & 2.22 & 3.29 & 2.57 \\
\hline \multicolumn{10}{|c|}{ Distances by log10-transformed indices } \\
\hline & $\mathrm{TT}$ & $\mathrm{EE}$ & $\mathrm{NN}$ & ENT(NT) & $\mathrm{ENN}(\mathrm{N})$ & $\mathrm{EE}(\mathrm{E}) \mathrm{N}$ & EEN & ANT & EENT \\
\hline $\mathrm{EE}$ & 1.96 & & & & & & & & \\
\hline $\mathrm{NN}$ & 2.66 & 3.32 & & & & & & & \\
\hline ENT(NT) & 1.24 & 2.23 & 2.31 & & & & & & \\
\hline $\mathrm{ENN}(\mathrm{N})$ & 2.25 & 2.92 & 1.39 & 1.84 & & & & & \\
\hline $\mathrm{EE}(\mathrm{E}) \mathrm{N}$ & 1.73 & 2.45 & 1.81 & 1.82 & 1.48 & & & & \\
\hline EEN & 2.12 & 2.25 & 2.37 & 1.89 & 2.19 & 1.94 & & & \\
\hline ATN & 2.27 & 2.17 & 3.49 & 1.99 & 3.10 & 3.01 & 2.38 & & \\
\hline EETN & 2.37 & 2.59 & 2.61 & 2.36 & 2.37 & 2.08 & 1.37 & 2.95 & \\
\hline EN & 2.18 & 2.90 & 1.86 & 1.92 & 1.51 & 1.15 & 2.13 & 3.28 & 2.52 \\
\hline
\end{tabular}

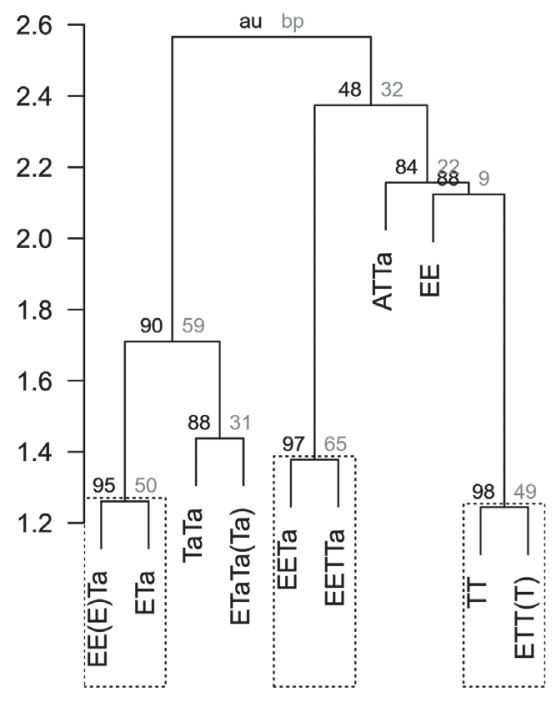

$\log 10$ measurements

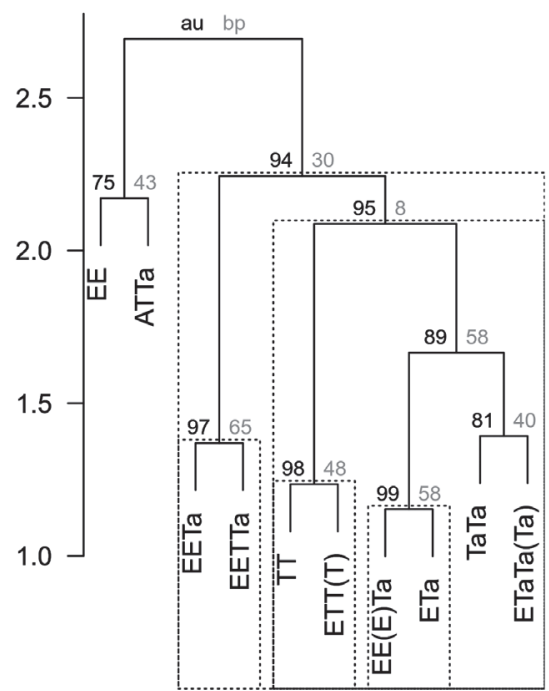

$\log 10$ indices

Fig. 6. UPGMA clustering of biotypes by Mahalanobis distances calculated for body measurements and indices separately. Rectangles bounds the clusters with more than $90 \%$ AU-support. 


\section{Discussion}

The data on variability of plastic traits which reflect body's absolute parameters and proportions in spined loaches specimens of the complex Cobitis elongatoides-C. taeniaC. tanaitica, show that the analyzed hybrid forms and parental species often do differ significantly in the traits' variability patterns in one- or multidimensional space. However, the differences are not significant enough that measurements and proportions could be used to draw a key for species and biotypes with 95-100 \% true identifications. Also, the difficulties of identification lie not only in the impossibility to clearly distinguish hybrid forms which should have intermediate morphology relative to parental species, but also, surprisingly, parental species themselves. It pertains first of all to C. elongatoides and C. taenia, which are highly genetically differentiated (Šlechtova et al., 2000; Bohlen et al., 2002), unlike C. taenia and C. tanaitica which have insignificant genetic differences (Mezhzherin, Pavlenko, 2009).

On the whole, the data on biotope variability in river systems of Ukraine correspond to results obtained for spined loaches from Poland (Kotusz, 2000, 2008). In the pooled sample of spined loaches, multidimensional analysis not only wiped the borders between species and biotypes; there was no logical structure to their morphological differentiation which a priori should correspond to the degree of genetic difference between the parent species and gene dosage in polyploids. The reasons for this incongruity could be indistinct species differences, absence of additive genetic interactions and the effect of the environment on plastic traits, which is evidently no less if not stronger than genes' influence on the phenotype. And thus geographical variability within a species masks interspecies variability.

The difficulty with identification using plastic traits does not, theoretically, mean impossibility to distinctly identify them using qualitative exterior parameters, such as the details of Gambetta zones, shape and number of the melanistic spots at the base of the tail fin, structure of scales and the Canestrini's organ (Kotusz, 2008). Yet in practice, the traits are not widely used for the C. elongatoides-C. taenia-C. tanaitica species group. Such a trait as the shape of Canestrini's organ can be used only for males and so only for diploids; scale shape seems to be fairly subjective, and specificity in Gambetta zones is drowned by individual and geographical variability. Thus, distinguishing the species appears practically impossible. A similar situation arose in another diploid-polyploid complex of European freshwater fishes, Carassius (superspecies auratus). In Ukrainian waters it includes one parental species and three hybrid clone biotypes. The discrimination level in the group turned out to be quite low (Mezhzherin, Kokodiy, 2009). When a complex of plastic and meristic traits was used, it reached $86 \%$, and for plastic traits alone $-80 \%$, which is similar to resolution for spined loaches.

The notion of twin species was designed in 1960s for outwardly indistinguishable but genetically and reproductively isolated taxonomical entities (Mayr, 1966). Recently, it sees more use as a metaphor but not a real scientific description. It turned out that for most of the so-called twin species, it is possible to discriminate them based on some exterior parameters and on distinct genetic specimen series. This means that the problem lies not in the absence of diagnostic traits as such but in the need to interpret them truly; whereas in spined loaches $C$. elongatoides-C. taenia-C. tanaitica the concept of twin species probably found its pure embodiment. The species of the group do reliably differ in karyotypes, biochemical markers and DNA sequences, yet have no distinct morphological diagnosis.

\section{References}

Berg, L. S. 1949. Freshwater Fish of the USSR and adjacent countries. Part 2. Izd-vo Akad. Nauk SSSR, Leningrad, 470-1382 [In Rassian].

Bohlen, J., Rab, P. 2001. Species and hybrid richness in spined loaches of the genus Cobitis (Teleostei: Cobitidae), with a cheklist of European forms and suggestions for conservation. J. Fish. Biol., 59 (1), 75-89. 
Bohlen, J., Rab, P., Šlechtova, V., Rabova, M., Ritterbusch, D., Freyhof, J. 2002.Hybridogenous biotypes in spined loaches (genus Cobitis) in Germany withi mplications for conservation. In: Colares-Pereira, M. J., Cowx, I. G., Coelho, M. M., eds. Conservation off reshwater fishes: options for the future. Wiley-Blackwell, 311-321.

Boroń, A. 2003. Karyotypes and cytogenetic diversity of the genus Cobitis (Pisces: Cobitidae) in Poland: a review. Cytogenetic evidence for a hybrid origin of some Cobitis triploids. Folia Biol., 51. (suppl.), 49-54.

Chen, Y., Sui, X., Liang, N., , Y. 2015. Two new species of the genus Cobitis Linnaeus from southern China. Chinese J. Oceanol. Limnol, 34 (3), 517-525.

Culing, M. A., Janko, K., Boroń, A., Vasil'ev, V. P, Cote, I., Hewitt, G. M. 2006. European colonization by the spined loach (Cobitis taenia) from Ponto-Caspian refugia based on mitochondrial DNA variation. Mol. Ecol., 15 (1), 173-190.

Fish base. https://www.fishbase.de/summary/FamilySummary.php?ID=127

Janko, K., Kotlik, P., Rab P. 2003. Evolutionary of asexual hybrid (Teleostei: Cichlidae) inferred from phylogenetic analysis mitochondrial DNA variation. J. Evol. Biol., 16 (6), 1280-1287.

Janko, K., Culing, M. A., Rab, P., Kotlik, P. 2005. Ice age cloning - comparison of the Quaternary evolutionary histories of sexual and clonal forms of spiny loaches (Cobitis, Teleostei) using the analysis of mitochondrial DNA variation. Mol. Ecol., 14 (10), 2991-3004.

Janko, K., Flajšhnanas, M., Choleva, L. et al. 2007. Diversity of European spined loaches (genus Cobitis L.,): an update of the geographic distribution of the Cobitis taenia hybrid complex with a description of new molecular tools for species and hybrid determination. J. Fish. Biol., 71 (2), 387-408.

Kotusz, J. 2000. Intra- and interpopulation morphological variability in variability in diploid and varied-ploidy Cobitis from Poland. Fol. Zool., 49 (Suppl. 1), 219-226.

Kotusz, J. 2008. Morphological relationships between polyploidy hybrid spined loaches of the genus Cobitis (Teleostei: Cobitidae) and their parental species. Ann. Zool., 58 (4), 891-905.

Mayr, E. 1966. Animal species and evolution. Belknap Pres, Harvard Universyty, 1-797.

Mezhzherin, S. V., Chudakorova, T. Yu. 2002. Genetic structure of diploid-polyploid spined loaches complex Cobitis taenia (Cypriniformes: Cobitidae) of the Middle Dnieper basin. Rus. J. Genet, 38 (1), 86-92.

Mezhzherin, S. V., Kokodiy, S. V. 2009. Morphological variability and differentiation of the goldfish, Carassius auratus, and Prussian carp, C. gibelio, (Cypriniformes, Cyprinidae) in reservoirs of Ukraine. Vestnik Zoologii, 48 (1), 39-50 [In Russian].

Mezhzherin, S. V., Pavlenko, L. I. 2007. A case of hybridization in loaches (Osteichthies: Cobitidae: Cobitis) determing genetic instability and expansion. Cytol. Genet., 41 (4), 218-225.

Mezhzherin, S. V., Pavlenko, L. I. 2009. Spined loaches(Cypriniformes: Cobitidae: Cobitis) of Ukraine waters, genetic boundaries of the species and natural hybridization. Uzhhorod University Scientific Herald. Ser. Biol., 25, 146-154 [In Russian].

Mezhzherin, S. V., Pavlenko, L. I. 2010. Genetic diversity, origin and distribition tendencies of polyploid spined loaches (Cypriniformes, Cobitidae, Cobitis) within Ukraine. Cytol. Genet., 44 (5), 65-77.

Mezhzherin, S. V., Pukhtayevych, P. P., Tsyba, A. A. 2014. Absorbing hybridization of Cobitis taenia and Sabanejewia aurata (Cypriniformes, Cobitidae) in water reservoirs of Northern Ukraine connected with diploid-polyploid complex formation. Vestnik Zoologii, 48 (6), 503-510.

Mitteroecker, P., Bookstein, F. 2011. Linear discrimination, ordination, and the visualization of selection gradients in modern morphometrics. Evol. Biol., 38 (1), 100-114.

Mousavi-Sabet, H., Vatandoust, S., Esmaeili, H. R., Geiger, M. F. Freyhof, J. 2015. Cobitis avicennae, a new species of spined loach from the Tigris River drainage (Teleostei: Cobitidae). Zootaxa, 3914 (5), 558-568.

Oksanen, J., Blanchet, F. G., Kindt, R. et al. 2018. Vegan: community ecology package. R package version 2.5-3. https://cran.r-project.org/web/packages/vegan

Peacock, F. C., Bunting, S. L., Queen, K. G. 1965. Serum protein electrophoresis in acrilamyde gel patterns from normal human subjects. Science, 147 (3664), 1451-1455.

Perdices, A., Bohlen, J., Šlechtová, V., Doadrio I. 2016. Molecular evidence for multiple origins of the European spined loaches (Teleostei, Cobitidae). PLoS ONE, 11, 1. doi:10.1371/journal. pone.0144628

Pravdin, I. F. 1966. Guide to the study of fish. Food Industry, Moscow, 1-376 [In Russian].

Rab, P., Raboba, M., Bohlen, J., Lusk S. 2000. Genetic differentiation of the two hybrid diploid-polyploid complexes of loaches, genus Cobitis (Cobitidae) involving C. taenia, C. elongatoides and C. sp. in the Czech Republic: Karyotypes and cytogenetic diversity. Folia Zool., 49 (Suppl. I), 55-66.

$R$ Core Team. A language and environment for statistical computing. 2017. R Foundation for Statistical Computing, Vienna, Austria. https://www.R-project.org/.

Schlager, S. 2017. Morpho and Rvcg - Shape Analysis in R. In: Zheng, G., Li, S., Szekely, G., eds. Statistical Shape and Deformation Analysis. Academic Press, 217-256.

Sezaki, K., Kobayashi, H., Nakamura, M. 1977. Size of erythrocytes in the diploid and triplod specimens of Carassius auratus langsdorfi. Jap. J. Ichthyol., 24 (2), 135-140.

Šlechtova, V., Luskova, V., Šlechta, V. et al. 2000. Genetic differentiation of two diploid-polyploid complexes of spined loach, genus Cobitis (Cobitidae), in the Czech Republic, involving C. taenia, C. elongatoides, and C. spp.: allozyme interpopulation and interspecific differences. Folia Zool., 49 (1), 67-78. 
Suzuki, R., Shimodaira, H., Suzuki, M. R. 2015. Package 'pvclust'. R topics documented, 14. https://cran.rproject.org/web/packages/pvclust

Ueno, K., Iwai, S., Ojima, Y. 1980. Karyotypes and geographical distribution in the genus Cobitis (Cobitidae). Bull. Japan Soc. Sci. Fish, 46 (1), 9-18.

Ueno, K., Ojima, Y. 1976. Diploid-tetraploid complexes in the genus Cobitis (Cobitidae, Cyprinida). Proc. Japan Acad., 52, 446-449.

Vasil'eva, E. D., Vasil'ev, V. P. 2012. Cobitis amphilekta sp. nova, a new species of spined loaches (Cobitidae, Cypriniformes) from the Caspian Sea Basin. J. Ichthyol., 52, 3, 200-206.

Vasil'ev, V. P. 1985. Evolutionary karyology of fishes. Nauka, Moscow, 1-299 [In Russian].

Vasil'ev, V. P., Vasil'eva, E. D. 1998. Sibling species in the genus Cobitis (Cobitidae) Cobitis rossomeridionalis sp. nova. J. Ichthyol., 38 (8), 580-590 [In Russian].

Wheeler, B., Torchiano, M., \& Torchiano, M. M. 2016. Package 'lmPerm'. R package version, 2.1.0. https:// cran.r-project.org/web/packages/lmPerm

Received 22 March 2019

Accepted 25 August 2020 